\title{
Pharmacokinetics of Orally Administered Prednisolone in Alpacas
}

\author{
Ricardo Videla ${ }^{1 *}$, Carla Sommardahl ${ }^{1}$, Joe Smith ${ }^{1,2}$, Deanna M. W. Schaefer ${ }^{3}$ and \\ Sherry Cox ${ }^{3}$ \\ ${ }^{1}$ Department of Large Animal Clinical Sciences, University of Tennessee, Knoxville, Knoxville, TN, United States, \\ ${ }^{2}$ Department of Biomedical Sciences, lowa State University, Ames, IA, United States, ${ }^{3}$ Department of Biomedical and \\ Diagnostic Sciences, University of Tennessee, Knoxville, Knoxville, TN, United States
}

\section{OPEN ACCESS}

Edited by:

Nora Mestorino,

National University of La

Plata, Argentina

Reviewed by:

Mohamed Aboubakr,

Benha University, Egypt Heather Knych,

University of California, Davis, United States

${ }^{*}$ Correspondence: Ricardo Videla rvidela@utk.edu

Specialty section: This article was submitted to Veterinary Pharmacology and Toxicology,

a section of the journal

Frontiers in Veterinary Science

Received: 22 July 2021 Accepted: 06 September 2021 Published: 22 October 2021

Citation:

Videla R, Sommardahl C, Smith J, Schaefer DMW and Cox S (2021)

Pharmacokinetics of Orally Administered Prednisolone in Alpacas.

Front. Vet. Sci. 8:745890

doi: 10.3389/fvets.2021.745890
This study aimed to determine the pharmacokinetics of prednisolone following intravenous and oral administration in healthy adult alpacas. Healthy adult alpacas were given prednisolone (IV, $n=4)$, as well as orally (PO, $n=6$ ). Prednisolone was administered IV once (1 mg/kg). Oral administration was once daily for 5 days (2 mg/kg). Each treatment was separated by a minimum 4 month washout period. Samples were collected at 0 (pre-administration), $0.083,0.167,0.25,0.5,0.75,1,2,4,8,12$, and $24 \mathrm{~h}$ after IV administration, and at 0 (pre-administration), 0.25, 0.5, 0.75, 1, 2, 4, 8, 12, 24 after the first and $5^{\text {th }} \mathrm{PO}$ administration. Samples were also taken for serial complete blood count and biochemistry analysis. Prednisolone concentration was determined by high pressure liquid chromatography. Non-compartmental pharmacokinetic parameters were then determined. After IV administration clearance was $347 \mathrm{~mL} / \mathrm{kg} / \mathrm{hr}$, elimination half-life was $2.98 \mathrm{~h}$, and area under the curve was 2,940 h*ng/mL. After initial and fifth oral administration elimination half-life was 5.27 and $5.39 \mathrm{~h}$; maximum concentration was 74 and $68 \mathrm{ng} / \mathrm{mL}$; time to maximum concentration was 2.67 and $2.33 \mathrm{~h}$; and area under the curve was 713 and $660 \mathrm{hr} * \mathrm{ng} / \mathrm{mL}$. Oral bioavailability was determined to be $13.7 \%$. Packed cell volume, hemoglobin, and red blood cell counts were significantly decreased 5 days after the first PO administration, and serum glucose was significantly elevated 5 days after the first PO administration. In conclusion, serum concentrations of prednisolone after IV and PO administration appear to be similar to other veterinary species. Future research will be needed to determine the pharmacodynamics of prednisolone in alpacas.

Keywords: prednisolone, pharmacokinetics, prednisone, alpaca, Vicugna pacos

\section{INTRODUCTION}

The growing population of South American camelids within the United States has resulted in the need for veterinary care of both common and uncommon disease processes in these species. There are currently no drugs approved by the Food and Drug Administration for camelids and pharmaceutical companies cannot economically justify seeking approval of drugs in these species. The pharmacokinetics for multiple classes of drugs for camelids have been described; including antibiotics (1-5), non-steroidal anti-inflammatories $(6,7)$, 
gastric acid suppressants (8-10), opioids (11, 12), and other pharmaceuticals $(13,14)$, however, no pharmacokinetic studies for prednisolone exist for camelids. Many of the dosage regimens used in camelids are empirical or extrapolated from species with different physiology and metabolism. However, several drugs have dissimilar kinetics in camelids as compared to other livestock species which can result in improper dosing or unwanted side effects. There is a need for understanding the pharmacokinetics of drugs in camelids to optimize medical treatment and reduce side effects.

Prednisone and prednisolone are synthetic analogs of cortisol. Prednisone is more affordable than prednisolone but it needs to be converted by the liver to its active metabolite, prednisolone, to have a therapeutic effect. Prednisone is readily converted into prednisolone in humans and dogs $(15,16)$. However, in the cat and horse there is evidence that prednisone is not efficiently metabolized to prednisolone, and therefore not therapeutic $(17,18)$. There are no published studies to date to determine if camelids are able to convert prednisone into prednisolone. Prednisolone is available in oral and injectable formulations for use in some domestic species. In camelids, oral administration would be preferred as venous access can be challenging for most owners to administer and stressful to the animal.

Even though steroids are fundamental for the treatment of certain conditions such as autoimmune diseases, there can be adverse side effects which often make practitioners wary of using this therapy. Exogenous steroids can cause suppression of the hypothalamo-pituitary-adrenal (HPA) axis, which often leads to harmful side effects if discontinued abruptly, especially after prolonged therapy. Other side effects include polyuria/polydipsia, changes in appetite, muscle atrophy, susceptibility to infection, gastrointestinal ulceration, changes in liver function, and abortion (19). Given the prominent adverse side effects of glucocorticoid therapy, it is important to use the lowest effective dose possible. Determining the pharmacokinetics of oral prednisolone is an essential step in determining the most appropriate dose for camelids.

To date there are no studies analyzing the pharmacokinetics of orally administered corticosteroids in camelids. The aim of this study is to determine the bioavailability and pharmacokinetics of prednisolone in alpacas after oral administration, and to evaluate possible side effects during and after a 5 day treatment. We hypothesize that oral administration of prednisolone will result in blood levels comparable to levels of clinical value in other species and that a 5 day course of treatment will result in no or minimal side effects.

\section{MATERIALS AND METHODS}

This study was approved by the Institutional Animal Care and Use Committee of the University of Tennessee (protocol \#24001215). Four clinically healthy alpacas were used, housed in box stalls at least $24 \mathrm{~h}$ before and during the experiment. Alpaca ages and weights (mean \pm standard deviation) were $8.0 \pm 4.3$ years and $68.8 \pm 9.7 \mathrm{kgs}$. Two intravenous jugular catheters were placed (one in each jugular vein) the day prior to the intravenous component of the study. Each alpaca $(n=4)$ was administered $1.0 \mathrm{mg} / \mathrm{kg}$ prednisolone (Prednisolone, USP, Rockville, MD, USA), intravenously in one catheter and samples were collected from the other catheter. Blood samples were collected at 0 (preadministration), 5, 10, 15, 30, and $45 \mathrm{~min}$ as well as 1, 2, 4, 8, 12, and $24 \mathrm{~h}$ after administration and were centrifuged at $1,000 \mathrm{~g}$ for $15 \mathrm{~min}$. Plasma was removed and stored at $-80^{\circ} \mathrm{C}$ until analysis.

After a washout period of 4 months six alpacas were housed in box stalls and had intravenous catheters placed in the jugular vein. Prednisolone tablets (PrednisTab ${ }^{\circledR}$, Lloyd Inc., Shenandoah, IA), were dosed at $2 \mathrm{mg} / \mathrm{kg}$ every $24 \mathrm{~h}$ for 5 days to six alpacas. Blood samples were collected at 0 (preadministration), 15, 30, and $45 \mathrm{~min}$ as well as 1, 2, 4, 8, 12, 24 (pre-second administration) hours. On days 2-4 blood samples were collected at peak ( $2 \mathrm{~h}$ after administration) and trough times (immediately prior to drug administration). On the $5^{\text {th }}$ day samples were collected at 0 (pre-administration of the fifth dose), 15, 30, and $45 \mathrm{~min}$ as well as 1, 2, 4,8 , and $12 \mathrm{~h}$ after the last administration. Samples were immediately centrifuged after collection with the serum stored at $-80^{\circ} \mathrm{C}$ until analysis. Additionally, before the initial drug administration (day 1), on the day of the last dose (day 5), and 5 days after the last dose (day 10), whole blood was collected into a tube containing ethylenediaminetetraacetic acid (EDTA) anticoagulant for complete blood count (CBC) and a tube containing heparin anticoagulant for plasma chemistry testing. These samples were submitted to the University of Tennessee Veterinary Medical Center (UTCVM) clinical pathology laboratory, with testing performed according to the laboratory standard operating procedure using an ADVIA 2,120 hematology analyzer (Siemens, Munich, Germany) and a Cobas C501 chemistry analyzer (Roche Diagnostics, Basel, Switzerland) (20).

Analysis of prednisolone in plasma samples was conducted using reversed phase HPLC. The system consisted of a 2695 separations module and a 2487 UV detector (Waters, Milford, MA, USA.). Separation was attained on a Waters Symmetry Shield $\mathrm{RP}_{18} 4.6 \times 150 \mathrm{~mm}(5 \mu \mathrm{m})$ protected by a $5 \mu \mathrm{m}$ Symmetry Shield $\mathrm{RP}_{18}$ guard column. The mobile phase was an isocratic mixture of $100 \mathrm{mM}$ ammonium acetate $\mathrm{pH} 4.0$ with concentrated glacial acetic acid and acetonitrile (70:30). It was prepared fresh daily using double-distilled, deionized water filtered $(0.22 \mu \mathrm{m})$ and degassed before use. The flow rate was $1.0 \mathrm{ml} / \mathrm{min}$ and UV absorbance was measured at $254 \mathrm{~nm}$.

Prednisolone was extracted from plasma samples using liquidliquid extraction. Briefly, previously frozen plasma samples were thawed and vortexed, and $500 \mu \mathrm{L}$ was transferred to a clean screw-top test tube followed by $25 \mu \mathrm{L}$ internal standard $(10 \mu \mathrm{g} / \mathrm{mL}$ methylprednisolone). Methylene chloride $(3 \mathrm{~mL})$ was added and the tubes were rocked for $20 \mathrm{~min}$ and then centrifuged for $20 \mathrm{~min}$ at $1,000 \mathrm{Xg}$. The organic layer was transferred to a clean tube and evaporated to dryness with nitrogen gas. Samples were reconstituted in $250 \mu \mathrm{L}$ of mobile phase and $100 \mu \mathrm{L}$ was analyzed.

Standard curves for plasma analysis were prepared by fortifying untreated, pooled alpaca plasma with prednisolone to produce a linear concentration range of $5-1,000 \mathrm{ng} / \mathrm{mL}$. 
Calibration samples were prepared exactly as plasma samples. Average recovery for prednisolone was $96 \%$ while intra and interassay variability ranged from 2.5 to $5.8 \%$ and 1.01 to $6.25 \%$, respectively. The lower limit of quantification was $5 \mathrm{ng} / \mathrm{mL}$ and the limit of detection was $2.5 \mathrm{ng} / \mathrm{mL}$.

\section{Pharmacokinetic Analysis}

Pharmacokinetic parameters for prednisolone were calculated using Phoenix WinNonlin 6.4 (Certara USA, Inc., Princeton, New Jersey 08540, USA). Values for elimination rate constant $\left(\lambda_{\mathrm{z}}\right)$, plasma half-life $\left(\mathrm{t}_{1 / 2}\right)$, plasma concentration back extrapolated to time $0\left(\mathrm{C}_{0}\right)$, maximum plasma concentration $\left(\mathrm{C}_{\max }\right)$, time to maximum plasma concentration $\left(\mathrm{T}_{\max }\right)$, total body clearance $(\mathrm{Cl})$, volume of distribution $\left(\mathrm{Vd}_{\text {area }}\right)$, apparent volume of distribution at steady-state $\left(\mathrm{Vd}_{\mathrm{ss}}\right)$, mean residence time $\left(\mathrm{MRT}_{0-\infty}\right)$, area under the plasma concentration time curve from time 0 to infinity $\left(\mathrm{AUC}_{0-\infty}\right)$ and area under the plasma concentration time curve from time 0 to last time point $\left(\mathrm{AUC}_{0-\text { Last }}\right)$ were calculated from non-compartmental analysis. The AUC was calculated using the log-linear trapezoidal rule. Variability in pharmacokinetic parameters was expressed as the standard deviation. In the case of the half-life, harmonic mean and pseudostandard deviation were used. Absolute systemic bioavailability (F) of prednisolone was calculated from noncompartmental parameters with the following equation:

$$
F=\frac{\mathrm{AUC}_{0-\infty(\mathrm{PO})} \times \operatorname{Dose}_{(\mathrm{IV})}}{\mathrm{AUC}_{0-\infty(\mathrm{IV})} \times \operatorname{Dose}_{(\mathrm{PO})}}
$$

The global extraction ratio $\left(\mathrm{E}_{\text {body }}\right)$ was calculated as reported by Toutain and Bousquet-Melou (21), with:

$$
\mathrm{E}_{\text {body }}=\text { Systemic clearance/Cardiac output }
$$

First calculated for each individual animal, and then combined for a mean value as previously described (22). With the alpaca cardiac output calculated as follows:

$$
\text { Cardiac output }=180 \times \mathrm{BW}(\mathrm{kg})^{-0.19}
$$

\section{Statistical Analysis}

Pharmacokinetic variables for prednisolone following oral and intravenous administration were calculated with a commercial computer software program (Phoenix 6.30, Pharsight Corp.). Pharmacokinetic parameters were tested for normality of distribution and equal variance (Graphpad Prism, La Jolla, CA) when data were normally distributed and had equal variances; a $t$ test was performed to determine whether differences existed between pharmacokinetic parameters from the IV prednisolone administration to Day 1 of oral administration, as well as Day 1 and Day 5 oral administration of prednisolone. Values of $P<0.05$ were considered significant for all statistical tests.

$\mathrm{CBC}$ and plasma chemistry results were inspected for abnormalities using alpaca reference intervals established in the UTVMC clinical pathology laboratory. Additionally, paired $t$ tests were used to evaluate for statistical difference between values on days 0, 5, and 10 (MedCalc Software Ltd, version 20.009).

\section{RESULTS}

Mean and standard deviation for plasma prednisolone concentrations for the single IV (Figure 1) and multidose PO study (Figure 2) are represented graphically. Pharmacokinetic parameters were summarized in Table 1. The mean of trough concentrations was similar on each of the days (D2, $18 \mathrm{ng} / \mathrm{mL}$; D3, $17 \mathrm{ng} / \mathrm{mL}$; and D4, $18 \mathrm{ng} / \mathrm{mL}$ ).

A non-compartmental model was used to evaluate plasma concentrations after both IV and PO dosing. The halflife, volume of distribution at steady-state and clearance for prednisolone after IV administration were $2.98 \pm 0.795 \mathrm{~h}, 1,295$ $\pm 242 \mathrm{~mL} / \mathrm{kg}, 347 \pm 54 \mathrm{~mL} / \mathrm{h} / \mathrm{kg}$, respectively. The half-life of prednisolone after oral dosing once a day for 5 days was $5.39 \pm$ $1.36 \mathrm{~h}$. The mean prednisolone bioavailability after oral dosing was $13.7 \%$. The extrapolated area under the curve was $6.0 \pm 4.6 \%$ for intravenous administration; $26.5 \pm 11.5 \%$ (after the first oral administration) and $25.7 \pm 8.6 \%$ (after last oral administration). Observed extraction ratio was $4.16 \pm 0.58$.

When IV vs. PO administration was statistically compared, significant differences were observed for lambda $Z(p=0.0153)$, area under the curve last $(p=<0.0001)$, mean residence time $(p=0.0129)$, and extrapolated area under the curve $(p=$ $0.0135)$. The $P$ value for comparison of elimination half-life was low $(p=0.0610)$, but not significantly different. There were no significant differences between any of the pharmacokinetic parameters between Day 1 and Day 5 for oral administration.

No clinical adverse effects were observed in any of the alpacas at any point during the study period. On the CBC, packed cell volume (PCV), hemoglobin, and red blood cell counts were significantly lower on day 5 compared to days 0 and 10 , and eosinophil numbers were significantly lower on day 10 compared to days 0 and 5, but all results were still within the reference intervals with the exception of one alpaca with a very mildly decreased red blood cell count on day 5 (Figure 3). Additionally, glucose was significantly higher on day 5 compared to days 0 and 10 and was above the reference interval in all 6 alpacas on that day. There were trends toward increasing white blood cell count, neutrophils, lymphocytes, and monocytes over time, but these were not statistically significant and did not go above the reference interval in any individuals. No other relevant changes were identified on $\mathrm{CBC}$ or chemistry results.

\section{DISCUSSION}

To the author's knowledge, this is the first study to determine the pharmacokinetics of prednisolone in alpacas. Glucocorticoids, such as prednisolone, are a powerful and effective therapeutic tool for many inflammatory disease processes. This class of drugs includes dexamethasone, prednisone, prednisolone, and hydrocortisone among others. They are used as antiinflammatory agents, immunosuppressives, for the treatment of lymphoma (cytotoxicity toward neoplastic lymphocytes), or to replace glucocorticoid activity in patients with adrenal insufficiency. They can be clinically beneficial in diseases where inflammation has detrimental effects such as uveitis, immune mediated diseases, asthma, inflammatory bowel disease, skin 


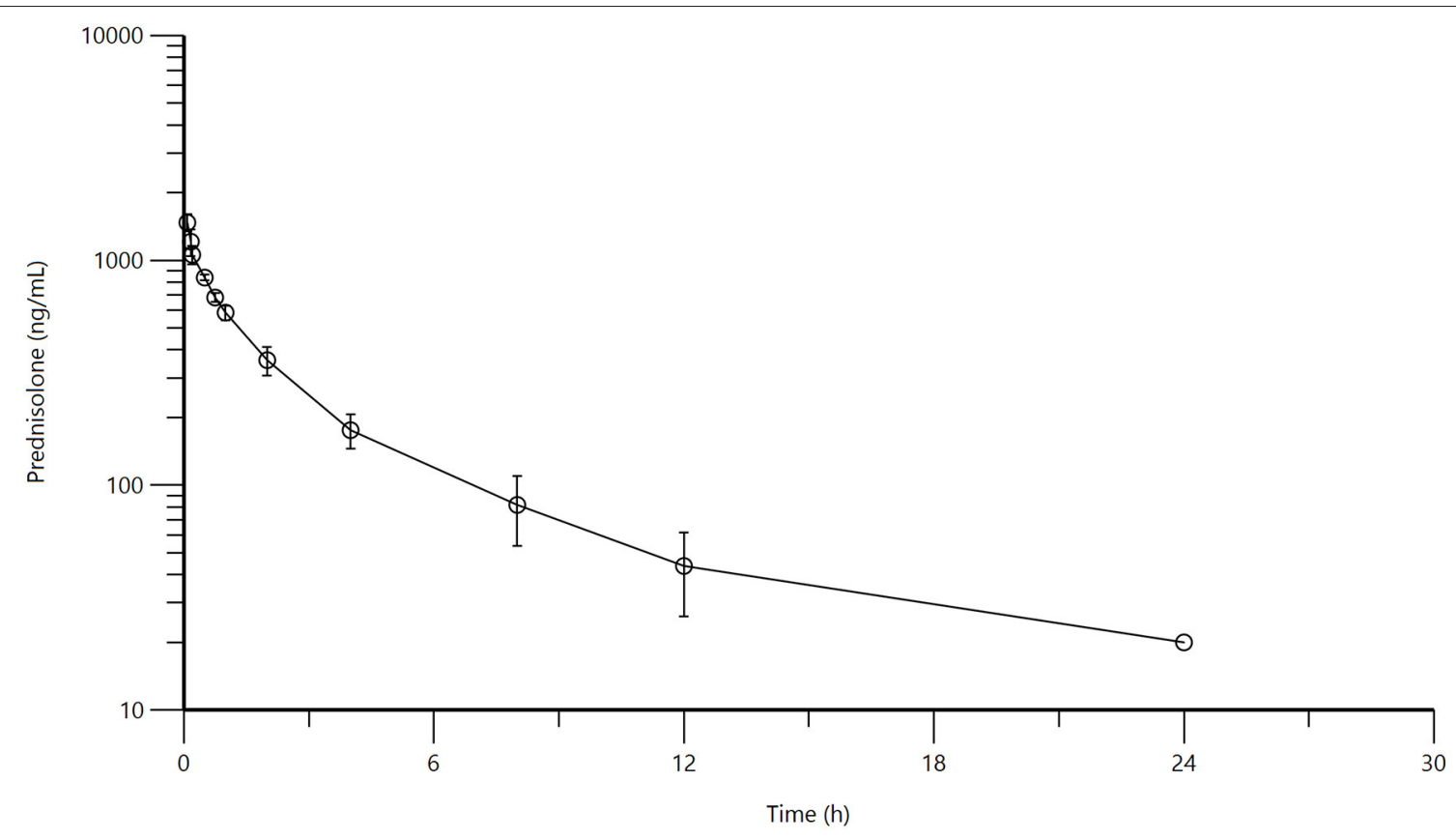

FIGURE 1 | Mean plasma prednisolone concentration (logarithmic scale) vs. time (h) profiles for adult alpacas ( $n=4)$ following intravenous (IV) single dose administration of $1.0 \mathrm{mg} / \mathrm{kg}$ of prednisolone. Mean is represented by an open circle with error bars representing standard deviation.

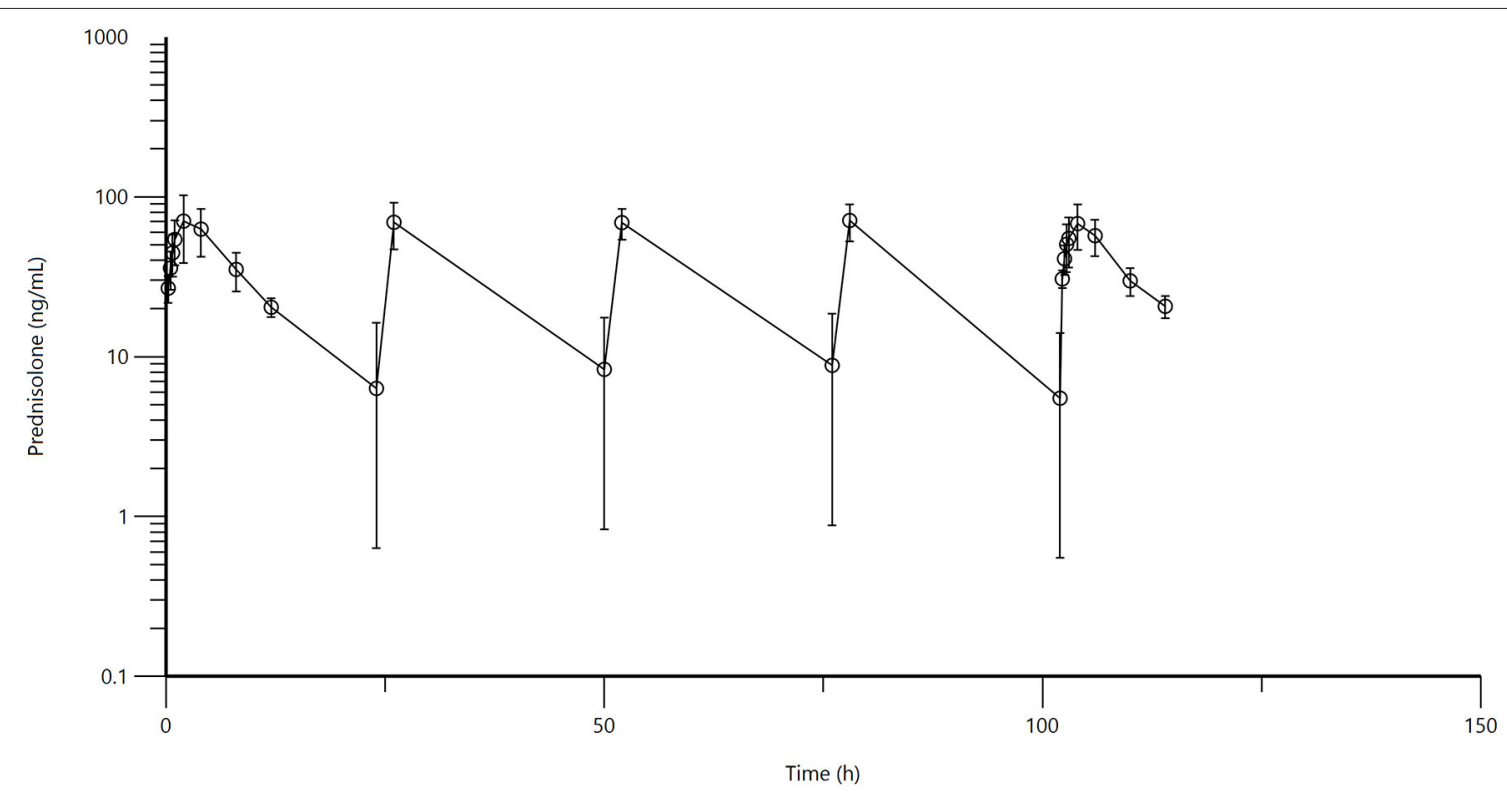

FIGURE 2 | Figure 1: Mean plasma prednisolone concentration (logarithmic scale) vs. time (hr) profiles for adult alpacas ( $n=6)$ following oral (PO) muliple dose administration of $2.0 \mathrm{mg} / \mathrm{kg}$ of prednisolone. Mean is represented by an open circle with error bars representing standard deviation. Doses were administered at 0,24 , 48,72 , and $96 \mathrm{~h}$.

allergies, certain neoplasias, lameness, and many neurologic conditions $(16,19)$. Descriptions of the use of prednisolone in the camelid medical literature are sparse. Historical reports describe prednisolone for chemotherapy of lymphosarcoma or lymphoma $(23,24)$. Anti-inflammatory doses are used for management of soft tissue injury from causes such as cerebrospinal nematodiasis and rattlesnake envenomation (25-27). Additional descriptions exist for the treatment of certain dermatological conditions (28). Topical use is described in the species for ophthalmologic cases (29). 
TABLE 1 | Pharmacokinetic parameters (mean \pm SD) in alpacas on Day 1 and Day 5 after multi-dose oral administration of 2 mg/kg prednisolone $(n=6)$ and $\mathrm{IV}$ administration of $1 \mathrm{mg} / \mathrm{kg}(n=4)$.

\begin{tabular}{|c|c|c|c|}
\hline Pharmacokinetic parameter & IV Administration & $\begin{array}{l}\text { PO Administration mean } \pm S D \\
\text { mean } \pm S D \\
\text { day } 1\end{array}$ & $\begin{array}{c}\text { PO Administration day } 5 \\
\text { mean } \pm \text { SD } \\
\text { day } 5\end{array}$ \\
\hline Terminal half-life* (h) & $2.98 \pm 0.795$ & $5.27 \pm 1.73$ & $5.39 \pm 1.36$ \\
\hline Elimination rate constant, $\lambda_{z}(1 / h)$ & $0.232 \pm 0.062$ & $0.131 \pm 0.043$ & $0.128 \pm 0.032$ \\
\hline $\mathrm{C}_{0}(\mathrm{ng} / \mathrm{mL})$ & $1,795 \pm 129$ & NA & NA \\
\hline $\mathrm{T}_{\max }(\mathrm{h})$ & NA & $2.67 \pm 1.03$ & $2.33 \pm 0.82$ \\
\hline $\mathrm{C}_{\max }(\mathrm{ng} / \mathrm{mL})$ & NA & $74 \pm 31$ & $68 \pm 21$ \\
\hline $\mathrm{Cl}(\mathrm{mL} / \mathrm{h} / \mathrm{kg})$ & $347 \pm 54$ & NA & NA \\
\hline $\mathrm{V}_{\mathrm{dss}}(\mathrm{mL} / \mathrm{kg})$ & $1,295 \pm 242$ & NA & NA \\
\hline $\mathrm{V}_{\mathrm{d}(\text { area) }}(\mathrm{mL} / \mathrm{kg})$ & $1,554 \pm 372$ & NA & NA \\
\hline $\mathrm{AUC}_{0-\infty}(\mathrm{h} \cdot \mathrm{ng} / \mathrm{mL})$ & $2,940 \pm 474$ & $713 \pm 140$ & $660 \pm 101$ \\
\hline $\mathrm{AUC}_{0}$-Last $(\mathrm{h} \cdot \mathrm{ng} / \mathrm{mL})$ & $2,797 \pm 480$ & $538 \pm 155$ & $499 \pm 111$ \\
\hline $\mathrm{AUC}_{\text {extrapolated }}(\%)$ & $6.0 \pm 4.6$ & $26.5 \pm 11.5$ & $25.7 \pm 8.6$ \\
\hline $\mathrm{MRT}_{0-\infty}(\mathrm{h})$ & $3.86 \pm 1.17$ & $9.22 \pm 3.17$ & $8.73 \pm 1.97$ \\
\hline$F(\%)$ & NA & $13.7 \pm 3.5$ & NA \\
\hline Extraction (\%) & $4.16 \pm 0.58$ & NA & NA \\
\hline
\end{tabular}

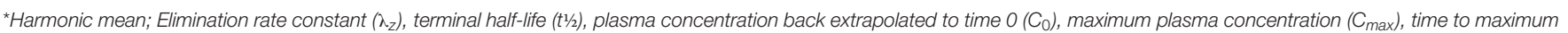

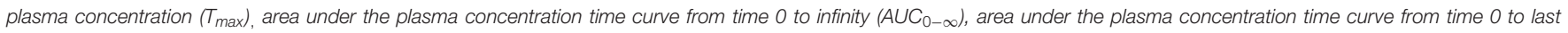

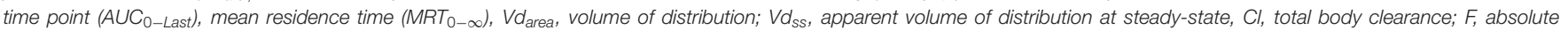
systemic bioavailability.

There are limited reports of pharmacokinetic data for prednisolone among large animal species. Studies exist for cattle, horses, and sheep (30-32). The clearance observed in the alpacas in this study $(0.347 \mathrm{~L} / \mathrm{kg} / \mathrm{hr})$ is similar to the ranges observed in horses $(0.235-0.374)$, as well as a cattle (0.42) and less than those reported for sheep $(0.93)(30,31,33)$. The elimination half-life of intravenous prednisolone reported in the alpacas in this study $(2.98 \mathrm{~h})$ is similar to the elimination half-life reported for cattle (3.6), but longer than horses (1.15-1.65) or sheep (0.85) after intravenous administration (30-33). Table 2 displays pharmacokinetic information for prednisolone in sheep, cattle, horses as well as the alpacas from this study. The bioavailability demonstrated by the alpacas in our study after oral administration was low (13.7\%). Reports of the oral bioavailability of prednisolone in large animal species are limited, however, this is similar to the low range of bioavailability (18\%) reported for prednisolone tablets in dogs (34). When comparing the pharmacokinetic parameters from our study to other large animal studies, it is important to note the limit of quantification. When limits of quantification are more sensitive, there is the potential for some pharmacokinetic parameters, such as elimination half-life, to be increased (22). All of the large animal assays employed similar sensitivity (2$3 \mathrm{ng} / \mathrm{mL}$ ), so it is likely that the pharmacokinetic parameter differences are true species differences instead of analytical method discrepancies.

Due to the multiple downstream effects of prednisolone, there currently are not many recommendations regarding therapeutic concentrations of prednisolone in the veterinary literature. In beagles administered oral prednisolone at $2.0 \mathrm{mg} / \mathrm{kg}$, maximum plasma concentrations of $58.2 \mathrm{ng} / \mathrm{mL}$ have been observed, this is similar to the maximum concentrations of 74 and $68 \mathrm{ng} / \mathrm{mL}$ observed in the alpacas in this study (35). This dosage in dogs has been described for the use as an anti-inflammatory agent as well as and antineoplastic agent $(19,36)$. While more investigation is necessary, this comparative observation may suggest that the oral dosing regimen used in the alpacas in this study may have similar plasma concentrations to other species.

Adverse effects reported in association with the administration of steroids in veterinary medicine include: leukocytosis with neutrophilia, monocytosis, lymphopenia, and eosinopenia. Also a mild elevation in albumin and in liver enzymes has been reported after treatment with steroids in dogs (37). In this alpaca study, there was a significantly decreased PCV, hemoglobin, and red blood cell count after 5 days of prednisolone administration, which was resolved at the recheck 5 days later. In the majority of individuals, all three of these parameters were still within the reference interval at all time points, so this may not be a clinically relevant change. Nevertheless, based on these results it may be worthwhile to periodically monitor for anemia in alpacas that are treated with prednisolone. There was also a mild but significant decrease in eosinophils noted at day 10. Eosinopenia can be a consequence of corticosteroids, but is unlikely to be clinically relevant. When serum biochemistry information was evaluated, the only consistent change across all animals was mild hyperglycemia noted 5 days after administration of prednisolone, which may be due to the gluconeogenic effects of corticosteroids.

Future directions for prednisonolone in alpacas include pharmacodynamic studies. One key area for further pharmacodynamic investigation is the use of prednisolone for anti-neoplastic therapy, considering the alpaca's role as 

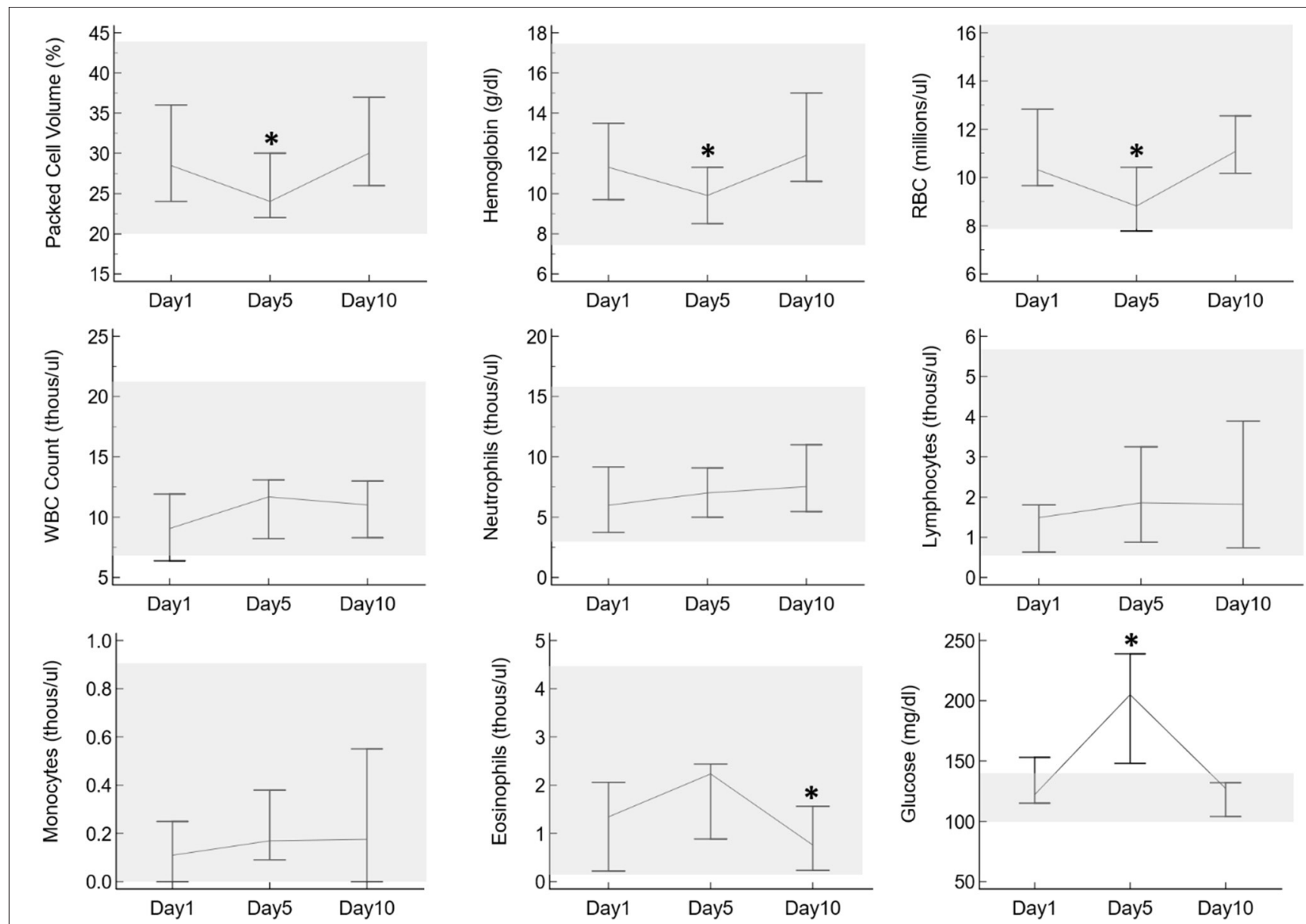

FIGURE 3 | Selected CBC and plasma biochemistry results from six alpacas before oral prednisolone (day 1), after 5 days of oral prednisolone (day 5), and after a 5 -day post-administration washout (day 10). The vertical lines indicate the range of results for each day, with lines connecting at the medians. The gray shaded boxes highlight the reference interval for each parameter as established for alpacas in the UTVMC clinical pathology laboratory. Asterisks indicate days in which results are significantly different from the other two days.

TABLE 2 | Comparative pharmacokinetic parameters for prednisolone in other large animal species.

\begin{tabular}{|c|c|c|c|c|c|c|c|}
\hline Species & Dose & Product & Route & $\mathrm{T}_{1 / 2}(\lambda \mathrm{z}) \mathrm{hr}$ & $\mathrm{Cl} \mathrm{l} / \mathbf{k g} / \mathrm{hr}$ & LLOQ & Reference \\
\hline Cattle & $600 \mu \mathrm{g} / \mathrm{kg}$ & Prednisolone 21-Sodium Succinate & IV & $3.6 \pm 1.177$ & $0.42 \pm 0.05$ & $2 \mathrm{ng} / \mathrm{mL}$ & Toutain et al. (31) \\
\hline Sheep & $1 \mathrm{mg} / \mathrm{kg}$ & Prednisolone & IV & $0.85 \pm 0.14$ & $0.93 \pm 0.13$ & $2.0 \mathrm{ng} / \mathrm{mL}$ & Alvinerie et al. (32) \\
\hline Horses & $450 \mathrm{mg}$ (total) & Prednisolone 21-Sodium Succinate & IV & $1.15 \pm 0.233$ & $0.374+/-0.047$ & $N / A$ & Chen et al. (33) \\
\hline Alpacas & $1 \mathrm{mg} / \mathrm{kg}$ & Prednisolone Sodium Succinate & IV & $2.98 \pm 0.795$ & $0.347 \pm 0.054$ & $2 \mathrm{ng} / \mathrm{mL}$ & Present study \\
\hline
\end{tabular}

a primarily companion animal, and the propensity of older alpacas to develop cancer $(24,38,39)$. Additional research is needed to elucidate the effects that body condition could have on the pharmacokinetics of prednisolone in alpacas, as overconditioning (increased body fat percentage) in some species, such as cats, is associated with higher serum concentrations (40). Another additional consideration is the effect of multiple drug administration on the pharmacokinetics of prednisolone in camelids. In dogs, the downregulation of P-glycoprotein via the administration of ketoconazole lead to an increased area under the curve for prednisolone due to the ketoconazole-induced P-glycoprotein inhibition (41). With the potential for biochemical and hematopoietic adverse effects, non-linear mixed-effect modeling could be utilized to investigate the potential factors for these adverse effects when prednisolone is administered to alpacas (42). Limitations of this study include the small sample size, however, in veterinary pharmacology studies sample sizes of 4-6 
animals are typically customary for describing pharmacokinetic parameters (43).

In conclusion, prednisolone administered at one IV dose of $1 \mathrm{mg} / \mathrm{kg}$ or 5 consecutive oral daily doses of $2 \mathrm{mg} / \mathrm{kg}$ was well-tolerated by alpacas in this study. Intravenous pharmacokinetics had similarities to cattle, specifically elimination half-life and plasma clearance. Evaluation of complete blood counts and serum biochemistry data suggested mild hyperglycemia and neutrophilia may be encountered from prednisolone administration. The concentrations reached by repeated oral administration are similar to those noted in other veterinary species when dosed at similar regimens. Future studies will be necessary to evaluate the pharmacodynamics of prednisolone when evaluating the effects of prednisolone administration to alpacas.

\section{DATA AVAILABILITY STATEMENT}

The original contributions presented in the study are included in the article/supplementary material, further inquiries can be directed to the corresponding author/s.

\section{REFERENCES}

1. Cox S, Sommardahl C, Seddighi R, Videla R, Hayes J, Pistole N, et al. Pharmacokinetics of intravenous and subcutaneous cefovecin in alpacas. J Vet Pharmacol Ther. (2015) 38:344-9. doi: 10.1111/jvp.12181

2. Pentecost RL, Niehaus AJ, Werle NA, Lakritz J. Pharmacokinetics of florfenicol after intravenous and intramuscular dosing in llamas. Res Vet Sci. (2013) 95:594-9. doi: 10.1016/j.rvsc.2013.05.009

3. Dechant JE, Rowe JD, Byrne BA, Wetzlich SE, Kieu HT, Tell LA. Pharmacokinetics of ceftiofur crystalline free acid after single and multiple subcutaneous administrations in healthy alpacas (Vicugna pacos). J Vet Pharmacol Ther. (2013) 36:122-9. doi: 10.1111/j.1365-2885.2012. 01395.x

4. Drew ML, Johnson L, Pugh D, Navarre CB, Taylor IT, Craigmill AL. Pharmacokinetics of ceftiofur in llamas and alpacas. $J$ Vet Pharmacol Ther. (2004) 27:13-20. doi: 10.1046/j.0140-7783.2003.00542.x

5. Chakwenya J, Lakritz J, Tyler J, Fales WH, James-Kracke M, Smith $\mathrm{K}$, et al. Pharmacokinetics and bioavailability of trimethoprimsulfamethoxazole in alpacas. J Vet Pharmacol Ther. (2002) 25:321-7. doi: 10.1046/j.1365-2885.2002.00425.x

6. Kreuder AJ, Coetzee JF, Wulf LW, Schleining JA, KuKanich B, Layman LL, et al. Bioavailability and pharmacokinetics of oral meloxicam in llamas. BMC Vet Res. (2012) 8:85. doi: 10.1186/1746-6148-8-85

7. Navarre CB, Ravis WR, Nagilla R, Deshmukh D, Simpkins A, Duran $\mathrm{SH}$, et al. Pharmacokinetics of flunixin meglumine in llamas following a single intravenous dose. J Vet Pharmacol Ther. (2001) 24:361-4. doi: 10.1046/j.1365-2885.2001.00356.x

8. Smith GW, Davis JL, Smith SM, Gerard MP, Campbell NB, Foster DM. Efficacy and pharmacokinetics of pantoprazole in alpacas. J Vet Intern Med. (2010) 24:949-55. doi: 10.1111/j.1939-1676.2010.0508.x

9. Sostek MB, Chen YS, Andersson T. Effect of timing of dosing in relation to food intake on the pharmacokinetics of esomeprazole. Br J Clin Pharmacol. (2007) 64:386-90. doi: 10.1111/j.1365-2125.2007.02889.x

10. Poulsen KP, Smith GW, Davis JL, Papich MG. Pharmacokinetics of oral omeprazole in llamas. J Vet Pharmacol Ther. (2005) 28:539-43. doi: 10.1111/j.1365-2885.2005.00696.x

11. Edmondson MA, Duran SH, Boothe DM, Stewart AJ, Ravis WR. Pharmacokinetics of tramadol and its major metabolites in alpacas following

\section{ETHICS STATEMENT}

The animal study was reviewed and approved by Institutional Animal Care And Use Committee.

\section{AUTHOR CONTRIBUTIONS}

RV, CS, DS, and SC developed the study design. RV and CS contributed to sample collection. SC developed the analytical method. SC and JS contributed to pharmacokinetic analysis. RV, CS, DS, JS, and SC all contributed to data interpretation and analysis. All authors contributed to manuscript construction.

\section{FUNDING}

This work was entirely funded by the Alpaca Research Foundation.

\section{ACKNOWLEDGMENTS}

The authors wish to acknowledge Joan Bailey Bergman, Molly White, and Kristen Gorden for their help with this study.

intravenous and oral administration. J Vet Pharmacol Ther. (2012) 35:389-96. doi: 10.1111/j.1365-2885.2011.01332.x

12. Uhrig SR, Papich MG, KuKanich B, Mama KR, Wagner AE, Chapman PL, et al. Pharmacokinetics and pharmacodynamics of morphine in llamas. Am J Vet Res. (2007) 68:25-34. doi: 10.2460/ajvr.68.1.25

13. Aarnes TK, Fry PR, Hubbell JA, Bednarski RM, Lerche P, Chen W, et al. Pharmacokinetics and pharmacodynamics of midazolam after intravenous and intramuscular administration in alpacas. Am J Vet Res. (2013) 74:294-9. doi: 10.2460/ajvr.74.2.294

14. Prado ME, Ryman JT, Boileau MJ, Martin-Jimenez T, Meibohm B. Pharmacokinetics of ponazuril after oral administration to healthy llamas (Lama glama). Am J Vet Res. (2011) 72:1386-9. doi: 10.2460/ajvr.72.10.1386

15. Colburn WA, Sibley CR, Buller RH. Comparative serum prednisone and prednisolone concentrations following prednisone or prednisolone administration to beagle dogs. J Pharm Sci. (1976) 65:997-1001. doi: 10.1002/jps.2600650711

16. Vogt M, Derendorf H, Krämer J, Junginger HE, Midha KK, Shah VP, et al. Biowaiver monographs for immediate release solid oral dosage forms: prednisolone. J Pharm Sci. (2007) 96:27-37. doi: 10.1002/jps.20768

17. Peroni DL, Stanley S, Kollias-Baker C, Robinson NE. Prednisone per os is likely to have limited efficacy in horses. Equine Vet J. (2002) 34:283-7. doi: $10.2746 / 042516402776186056$

18. Graham-Mize CA, Rosser EJ. (2004), Bioavailability and activity of prednisone and prednisolone in the feline patient. Vet Dermatol. 15:7-10. doi: 10.1111/j.1365-3164.2004.00410_2-6.x

19. Plumb DC. Plumbs Veterinary Drug Handbook. $7^{\text {th }}$ ed. Stockholm: WIS (2011). p 1139-45.

20. Viesselmann LC, Flatland B, Stokol T, Sisson S, Schaefer DMW. Evaluation of automated erythrocyte methodology in new world camelids using the ADVIA 2120 hematology analyzer. Vet Clin Patholo. (2019) 48:239-49. doi: $10.1111 /$ vcp. 12733

21. Toutain PL, Bousquet-Melou A. Plasma clearance. J Vet Pharmacol Ther. (2004) 27:415-25. doi: 10.1111/j.1365-2885.2004.00605.x

22. Smith JS, Coetzee JF, Fisher IWG, Borts DJ, Mochel JP. Pharmacokinetics of fentanyl citrate and norfentanyl in Holstein calves and effect of analytical performances on fentanyl parameter estimation. J Vet Pharmacol Ther. (2018) 41:555-61. doi: 10.1111/jvp.12501

23. Irwin JA. Lymphosarcoma in an alpaca. Can Vet J. (2001) 42:805-6. 
24. Marchionatti E, Van der Vekens E, Peters LM, Kaiponen TS, Veiga IB, Zanolari P. Solitary tracheal B-cell lymphoma in an adult alpaca (Vicugna pacos). BMC Vet Res. (2020) 16:429. doi: 10.1186/s12917-02002640-9

25. Bertin FR, Taylor SD. Cerebrospinal nematodiasis in 20 camelids. J Vet Intern Med. (2016) 30:1390-5. doi: 10.1111/jvim.13958

26. Breuer R, Merkatoris P, Tepley S, Dierks C, Klostermann C, Flaherty H, et al. Treatment of cerebrospinal nematodiasis in a Boer Buck. Vet Rec Case Rep. (2019) 7:e000706. doi: 10.1136/vetreccr-2018-000706

27. Sonis J, Hackett E, Callan R, Holt T, Hackett T. Prairie rattlesnake envenomation in 27 new world camelids. J Vet Intern Med. (2013) 27:1238-41. doi: 10.1111 /jvim. 12143

28. Rosychuk RA. Llama dermatology. Vet Clin North Am. (1989) 5:203-15. doi: 10.1016/S0749-0720(15)31010-0

29. Gionfriddo JR. Ophthalmology of south American camelids. Vet Clin. (2010) 26:531-55. doi: 10.1016/j.cvfa.2010.08.004

30. Toutain PL, Koritz GD, Alvinerie M, de Pomyers H, Ruckebusch Y. Prednisolone succinate and prednisolone acetate in cattle: pharmacokinetics and action on the adrenal gland. Am J Vet Res. (1985) 46:719-25.

31. Toutain PL, Brandon RA, de Pomyers H, Alvinerie M, Baggot JD. Dexamethasone and prednisolone in the horse: pharmacokinetics and action on the adrenal gland. Am J Vet Res. (1984) 45:1750-6.

32. Alvinerie M, Sutra JF, Galtier P, Toutain PL. Disposition of prednisolone in the course of subclinical fascioliasis in sheep. Xenobiotica. (1993) 23:483-93. doi: 10.3109/00498259309059389

33. Chen CL, Goldberg J, Gronwall RR. Pharmacokinetics of intravenously administration of prednisolone in the horse as determined by radioimmunoassay. Chin J Physiol. (1995) 38:1-6.

34. Tse FL, Welling PG. Prednisolone bioavailability in the dog. J Pharmacol Sci. (1977) 66:1751-4. doi: 10.1002/jps.2600661225

35. Sebbag L, Mochel JP. Pharmacokinetics of oral prednisone at various doses in dogs: preliminary findings using a naïve pooled-data approach. Front Vet Sci. (2020) 7:571457. doi: 10.3389/fvets.2020.571457

36. Sebbag L, Yan Y, Smith JS, Allbaugh RA, Wulf LW, Mochel JP. Tear fluid pharmacokinetics following oral prednisone administration in dogs with and without conjunctivitis. J Ocul Pharmacol Ther. (2019) 35:341-9. doi: 10.1089/jop.2019.0020

37. Martínez-Subiela S, Ginel PJ, Cerón JJ. Effects of different glucocorticoid treatments on serum acute phase proteins in dogs. Veterinary Record. (2004) 154:814-7. doi: 10.1136/vr.154.26.814
38. Hasbach AE, Stern AW. Pagetoid reticulosis (epitheliotropic cutaneous Tcell lymphoma) in an adult alpaca (Vicugna pacos). J Vet Diag Invest. (2016) 28:469-72. doi: 10.1177/1040638716645833

39. Faivre CM, Harm TM, Smith JS, Haynes JS, Dohlman TM. Mammary carcinoma in a geriatric alpaca. Vet Rec Case Rep. (2021) 9:e30. doi: $10.1002 /$ vrc2.30

40. Center SA, Randolph JF, Warner KL, Simpson KW, Rishniw M. Influence of body condition on plasma prednisolone and prednisone concentrations in clinically healthy cats after single oral dose administration. Res Vet Sci. (2013) 95:225-30. doi: 10.1016/j.rvsc.2013.02.004

41. Van der Heyden S, Croubels S, Gadeyne C, Ducatelle R, Daminet S, Escobar $\mathrm{HM}$, et al. Influence of P-glycoprotein modulation on plasma concentrations and pharmacokinetics of orally administered prednisolone in dogs. Am J Vet Res. (2012) 73:900-7. doi: 10.2460/ajvr.73.6.900

42. Bon C, Toutain PL, Concordet D, Gehring R, Martin-Jimenez T, Smith J, et al. Mathematical modeling and simulation in animal health. Part III: Using nonlinear mixed-effects to characterize and quantify variability in drug pharmacokinetics. J Vet Pharmacol Ther. (2018) 41:171-83. doi: $10.1111 /$ jvp. 12473

43. Riviere JE, Chittenden J. Study design and data analysis. In: Riviere JE, editor. Comparative Pharmacokinetics. 2 ed. Ames: Iowa State University Press. (2011). p. 311. doi: 10.1002/9780470959916.ch14

Conflict of Interest: The authors declare that the research was conducted in the absence of any commercial or financial relationships that could be construed as a potential conflict of interest.

Publisher's Note: All claims expressed in this article are solely those of the authors and do not necessarily represent those of their affiliated organizations, or those of the publisher, the editors and the reviewers. Any product that may be evaluated in this article, or claim that may be made by its manufacturer, is not guaranteed or endorsed by the publisher.

Copyright (C) 2021 Videla, Sommardahl, Smith, Schaefer and Cox. This is an openaccess article distributed under the terms of the Creative Commons Attribution License (CC BY). The use, distribution or reproduction in other forums is permitted, provided the original author(s) and the copyright owner(s) are credited and that the original publication in this journal is cited, in accordance with accepted academic practice. No use, distribution or reproduction is permitted which does not comply with these terms. 